to increase the risk six times. Fundamental determining factors to puerperal thromboembolism are combinations of relative late age and traumatic delivery, and there may well be others such as obesity and hypertensive states complicating pregnancy. It still remains uncertain how often it is these which prompt the administration of oestrogens to inhibit lactation.

At this stage of knowledge it may be concluded that, provided oestrogens have the inhibitory effect on breast activity which is credited to them, and which our observations lead us to accept as genuine, their administration does not increase the risk of puerperal thromboembolism to an unacceptable degree. This is true for women at low risk, but for those who are advanced in years and who are subjected to operative delivery involving considerable trauma there is some reason to hesitate to add one more predisposing factor, even if it be a minor one. Obesity and a past history of thromboembolic disorders might also sometimes be considered to be contraindications to the administration of oestrogens in the puerperium. When oestrogens are given, however, it would seem wise to use the lowest dose compatible with efficient inhibition of lactation.

A firm conclusion about the role of therapeutic doses of oestrogen in predisposing to puerperal thromboembolism may not be possible without controlled prospective studies, and these are already in progress. Because the incidence of clinicall evident disease is relatively low, this will take time. Meanwhile, the results of this retrospective study are reported to add to the evidence which needs to be collected from many sources.

\section{REFERENCES}

Arneil, G. C. (1967). Scottish Health Service Study, No. 6. Edinburgh. Burns, C. (1957). Med. Offr, 98, 205.

Daniel, D. G., Campbell, H., and Turnbull, A. C. (1967). Lancet, 2,

Daniel, D. G., Bloom, A. L., Giddings, J. C., Campbell, H., and Turnbull, A. C. (1968). Brit. med. F., 1, 801 .

Dykes, R. M. (1957). Lancet, 2, 230.

Garrey, M. M., Paterson, M. M., and Evans, J. M. (1964). Lancet, 2, 1057.

Hill, G. B., and Wilson, W. A. (1968). Med. Offr, 119, 147.

Hodge, C. (1967). Lancet, 2, 286.

Inman, W H. W., and Vessey, M. P. (1968). Brit. med. F., 2, 193.

Jeffcoate, T. N. A., Lister, Ursula M., Hargreaves, Betty, and Roberts, H. (1948). Brit med. F., 2, 809.

Jeffcoate, T. N. A., and Tindall, V. R. (1965). Aust. N.Z. F. Obstet. Gynaec., 5, 119.

Ministry of Health (1957, 1960, 1963, 1966). Reports on Confidential Enquirtes into Maternal Deaths, England and Wales. H.M.S.O., London.

Ministry of Health (1957a). Annual Report of the Chief Medical Officer. H.M.S.O., London.

Simpson Memorial Pavilion (1965). Annual Medical and Clinical Report. H.M.S.O., London.

Vessey, M. P., and Doll, R. (1968). Brit. med. F., 2, 199.

\title{
Circadian Variation of Glucose, Insulin, and Free Fatty Acids During Long-term Use of Oral Hypoglycaemic Agents in Diabetes Mellitus
}

\author{
A. N. RIGAS,* M.D. ; A. H. BITTLES, † F.I.M.L.T. ; D. R. HADDEN, $\ddagger$ M.D., M.R.C.P.ED. \\ D. A. D. MONTGOMERY,§ M.D., F.R.C.P.
}

Brit. med. F., 1968, 4, 25-28

\begin{abstract}
Cummary: The circadian rhythms of preprandial and $\$$ postprandial blood glucose, free fatty acids, and insulin levels were measured in groups of normal and of diabetic patients controlled by diet alone or by diet with tolbutamide, chlorpropamide, or metformin. All groups showed a greater insulin release after the first meal of the day than after subsequent meals. Diabetic patients controlled for more than two years on diguanide therapy showed the closest resemblance to non-diabetic control subjects. There was no significant difference between the values for diabetic patients on long-term control with diet alone and those on short- or long-acting sulphonylurea. The circadian rhythms disappeared in obese subjects on total starvation.
\end{abstract}

\section{Introduction}

The aim of therapy of maturity onset diabetes with oral hypoglycaemic agents is to achieve good long-term diabetic "control" in patients who do not respond to dietary measures alone. Good control of blood glucose levels has been said to

\footnotetext{
* Research Fellow.

+ Research Technician

¥ Physician, Metaholic Unit.

Physician-in-Charge, Metabolic Unit.

Sir George E Clark Metabolic Unit, Royal Victoria Hospital, Belfast, Northern Ireland.
}

prevent the development of vascular complications (Marble, 1965). Most studies of the action of hypoglycaemic agents have been concerned with the acute effect of the drug; there is little knowledge of what happens to patients in whom apparently good control is achieved over a prolonged period. Furthermore, possible differences between the available therapeutic agents have received little attention.

The present study was undertaken to document the changes of blood glucose, insulin, and free fatty acids in the fasting state and two hours after meals during the day in patients on different regimens (a restricted carbohydrate diet alone, or with tolbutamide, chlorpropamide, or metformin in addition), and to compare them with those found in normal persons and in obese patients undergoing total starvation.

\section{Patients and Methods}

Six groups of patients were studied (Table I). One of the two control groups consisted of three non-diabetic non-obese patients admitted to hospital for various medical conditions (simple goitre, Hashimoto's thyroiditis, cerebral angiospasm) who had a normal standard oral glucose tolerance test; the other group consisted of six normoglycaemic obese subjects who were undergoing a period of therapeutic total starvation. There were four groups of diabetic patients on restricted carbohydrate diet, or a similar diet in addition to three different oral hypoglycaemic agents. We attempted to make these groups 
as comparable as possible. The mean age of the six groups varied from 51 to 69 years. Diabetes had been diagnosed from three to six years previously, and the patients had received their respective therapy unchanged for two to five years. The dosage of the drug used was that required to maintain satis-

TABle I.-Mean Values for Age, Duration of Diabetes, Drug Therapy, and Weight Changes in the Six Groups Studied

\begin{tabular}{|c|c|c|c|c|c|c|c|c|c|}
\hline \multirow[t]{2}{*}{ Group } & \multirow[t]{2}{*}{ No. } & \multirow{2}{*}{ 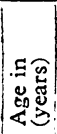 } & \multirow{2}{*}{ 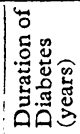 } & \multirow{2}{*}{ 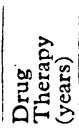 } & \multicolumn{2}{|c|}{$\begin{array}{c}\text { Initial } \\
\text { Weight }\end{array}$} & \multicolumn{2}{|c|}{$\begin{array}{l}\text { Present } \\
\text { Weight }\end{array}$} & \multirow{2}{*}{ 告 } \\
\hline & & & & & lb. & kg. & lb. & kg. & \\
\hline $\begin{array}{l}\text { Normal controls } \\
\text { Obese starvation } \\
\text { Diet } \\
\text { Diet }+ \text { tolbutamide } \\
\begin{array}{ll}\text { Diet }+ \text { chlorpropamide } \\
\text { Diet + metformin }\end{array}\end{array}$ & $\begin{array}{l}3 \\
6 \\
6 \\
5 \\
5 \\
5\end{array}$ & $\begin{array}{l}55 \\
51 \\
63 \\
69 \\
67 \\
53\end{array}$ & $\begin{array}{l}- \\
3 \\
5 \\
6 \\
4\end{array}$ & $\begin{array}{l}\bar{Z} \\
\overline{4} \\
5 \\
2\end{array}$ & $\begin{array}{l}\bar{Z} \\
151 \\
131 \\
146 \\
180\end{array}$ & $\begin{array}{l}68 \cdot 5 \\
59 \cdot 4 \\
66 \cdot 2 \\
81 \cdot 6\end{array}$ & $\begin{array}{l}146 \\
231 \\
136 \\
127 \\
139 \\
169\end{array}$ & $\begin{array}{r}66 \cdot 2 \\
104 \cdot 8 \\
61 \cdot 7 \\
57 \cdot 6 \\
63 \cdot 0 \\
76 \cdot 7\end{array}$ & $\begin{array}{l}- \\
10 \\
3 \\
5 \\
6\end{array}$ \\
\hline
\end{tabular}

factory blood sugar levels $(150 \mathrm{mg} . / 100 \mathrm{ml}$. or less two to three hours after a main meal), and consisted of tolbutamide 0.5-1 g. three times daily, chlorpropamide $250-500 \mathrm{mg}$. once daily, or metformin $0.5-1 \mathrm{~g}$. two or three times daily. The mean weights of the six groups at the time of clinical onset of diabetes and at the time of the present study are shown in Table I.

All the patients (group 2 excepted) were asked if they would accept a standard diet, presented as three meals a day of equal caloric composition, without any snacks, for a one-week period ; they were admitted to the metabolic wards for this time. This diet provided a total of 1,494 calories with $153 \mathrm{~g}$. of carbohydrate daily $(49,57$, and $47 \mathrm{~g}$. at breakfast, lunch, and tea respectively). No other food was permitted, but water was freely available. The ward routine of sleeping- and meal-times was followed, and the patients were ambulant between meals. On the fourth and sixth days venous blood samples were obtained before and two hours after each meal. These samples were centrifuged immediately in the ward and deep-frozen for subsequent analysis for insulin and free fatty acids. Venous blood for glucose estimation was also obtained, being stored, if necessary, at $4^{\circ} \mathrm{C}$. until assay. Blood glucose was measured by means of an autoanalyser, by a ferricyanide reduction technique (modified from Hoffman, 1937), insulin by the modified double antibody radio-immunoassay (Hales and Randle, 1963), and plasma free fatty acids by the method of Duncombe (1964).
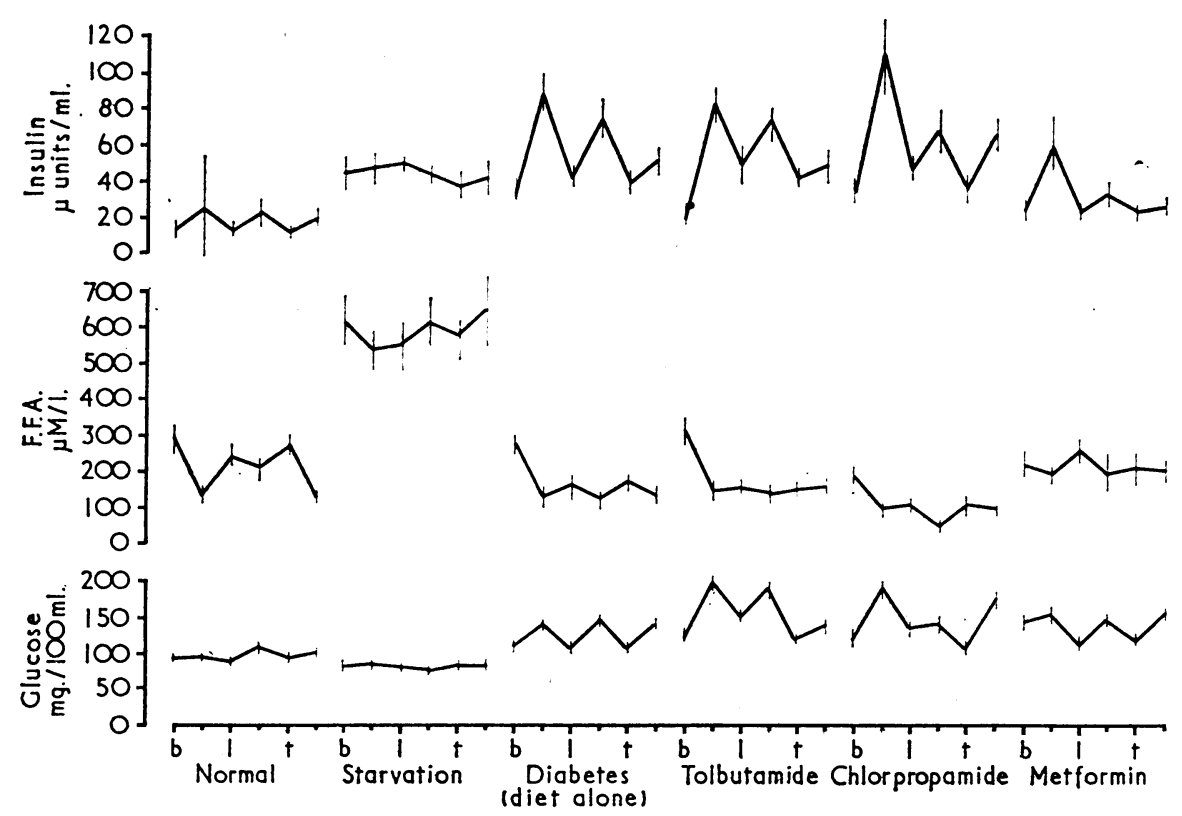

FIG. 1.-Means ( \pm standard error of mean) of the blood values throughout the day in the six groups studied (pooled results from day 4 and day 6 ). The times are represented by b (breakfast), 1 (lunch), and $t$ (tea), and two hours after each of these meals. (Approximate times of meals were breakfast 8.30 a.m., lunch 12.30 p.m., and tea 6 p.m.)
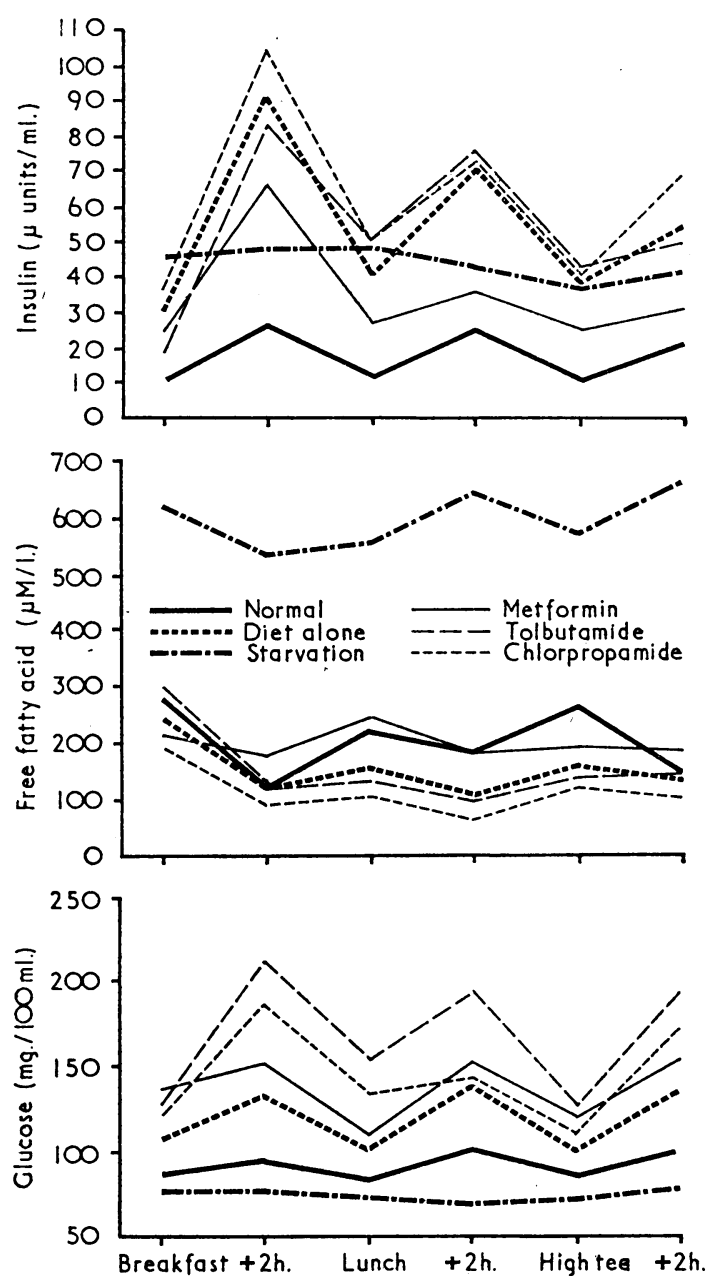

FIG. 2.-Mean circadian variations of glucose, free fatty acids, and insulin in the six groups.

\section{Results}

The results from day 4 to day 6 have been pooled, as there was no difference in the mean values obtained between these days. Fig. 1 shows the variation of blood glucose, insulin, and free fatty acids in normal subjects, diabetic patients, and obese subjects on total starvation. In the normal controls ${ }^{1}$ the blood sugar rose two hours after each meal, and was accompanied by an increase in plasma insulin and a fall in free fatty acids. In the obese subjects on total starvation the blood glucose levels were slightly lower, the insulin levels higher, and the free fatty acid levels considerably raised, but there was no evidence of any fluctuation during the period of observation. In the diabetic patients on diet alone the fasting blood glucose was $105 \mathrm{mg} . / 100 \mathrm{ml}$., and rose to about $140 \mathrm{mg} . / 100 \mathrm{ml}$. two hours after meals. The mean fasting insulin level was raised to $31 \mu \mathrm{u} . / \mathrm{ml}$., and was associated with an enhanced insulin response after meals, most marked after breakfast and falling off throughout the day. The free fatty acids were lower in general than those in the normal controls and showed less fluctuation.

${ }^{1}$ We will supply the full data on the biochemical findings on request. 
The groups taking tolbutamide and chlorpropamide show relatively similar patterns. Both have somewhat higher fasting blood glucose values with a greater degree of fluctuation but relatively similar insulin levels. The group on chlorpropamide have the greatest rise in insulin after breakfast and the lowest free fatty acid levels. The group receiving metformin showed the highest fasting blood glucose level, but the fluctuation was less and was associated with the lowest blood insulin levels of the four diabetic groups and less depression of free fatty acids. Again the after-breakfast rise in insulin was the greatest. Fig. 2 shows the same data on one chart. It will be seen that diabetic patients receiving metformin most closely approach the variations of the normal control group, and the mean of the three preprandial blood insulin levels through the day for this group $(24.3 \mu \mathrm{u} . / \mathrm{ml}$.) is significantly less than that for the diabetic patients controlled on diet alone $(37.5 \mu \mathrm{u} . / \mathrm{ml}$.) $(0.01>\mathrm{P}>0.001$, $t=3.16, \mathrm{~N}=64$ ).

An additional group of three patients was studied to find if there was any difference in these variables through the night between patients with long- and short-acting sulphonylureas. In this small group there was no difference between the blood glucose and insulin levels at 4 and 6 a.m. between patients taking tolbutamide $1 \mathrm{~g}$. three times daily or chlorpropamide $500 \mathrm{mg}$. once daily and one non-diabetic normal subject. No patient showed evidence of hypoglycaemia (Table II).

TABLE II.-Blood Insulin and Glucose Values in Three Patients at 4 and 6 a.m.

\begin{tabular}{|c|c|c|c|c|}
\hline \multirow{2}{*}{ Group } & \multicolumn{2}{|c|}{ Glucose $(\mathrm{mg} / 100 \mathrm{ml})}$. & \multicolumn{2}{|c|}{ Insulin $(\mu \mathrm{u} / \mathrm{ml})}$. \\
\hline & 4 a.m. & 6 a.m. & 4 a.m. & 6 a.m. \\
\hline $\begin{array}{l}\text { Normal subject } \\
\text { Diabetic diet }+ \text { tolbutamide } \\
\text { Diabetic diet }+ \text { chlorpropamide }\end{array} \quad \ldots$ & $\begin{array}{r}100 \\
86 \\
82\end{array}$ & $\begin{array}{r}65 \\
103 \\
82\end{array}$ & $\begin{array}{l}11 \\
16 \\
16\end{array}$ & $\begin{array}{r}14 \\
17 \\
8\end{array}$ \\
\hline
\end{tabular}

The "insulinogenic index" (Seltzer et al., 1967) has been derived from these results for the two-hour period after breakfast (Table III).

TABLB III.-Insulinogenic Indices (Seltzer et al., 1967) Calculated From Values of Glucose and Insulin Two Hours After Breakfast in Relation to Fasting Values

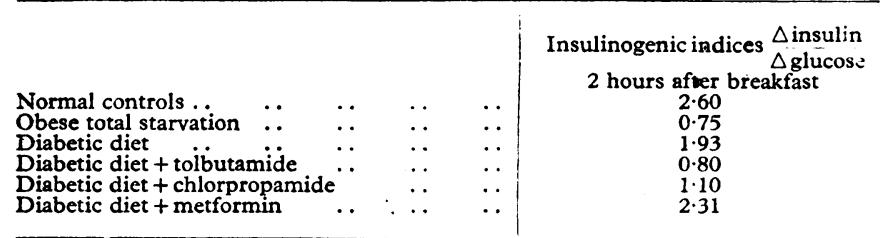

\section{Discussion}

In a comparative study of this type between groups of different patients conclusions can only be tentative, but we feel that reasonable matching in regard to age, duration of disease, and therapy has been achieved. The group taking metformin was initially the most obese, but all the groups had lost weight to a relatively similar degree by the time of study.

The variation of insulin and free fatty acid levels after glucose loading in similar diabetic subjects has been reported by Abramson and Arky (1967) after only three weeks' therapy. They found a similar rise in plasma insulin after chlorpropamide and a relative decrease after phenformin therapy; the fall in free fatty acids showed no significant differences between these groups. However, Reaven and Dray (1967) stated that the control of hyperglycaemia by chlorpropamide therapy for a longer period was followed by a just significant fall in plasma insulin response after a glucose load. This study makes no reference to the possible weight changes that may have occurred by the time of the second test, and it may be that factors other than those attributable to the drug explain their findings. Sheldon et al. (1966) found a persistent increased insulin production in response to oral glucose two days after withdrawing acetohexamide following three months' therapy. Their study differs in that it probably represents a long-term effect on $\beta$-cell function alone, whereas the present study is a composite of direct drug action and possible long-term changes in the insulin secretion apparatus.

Although the mean insulin levels are somewhat higher after meals in the two sulphonylurea-treated groups than in those on carbohydrate restriction alone, this difference does not reach significance, and probably represents only the slightly heavier weight and less good control of blood glucose in the groups in whom sulphonylureas had been prescribed. This finding is in keeping with the study of Chu et al. (1968), who found, after five weeks of chlorpropamide therapy, no evidence of increase in insulin secretion independent of the usual physiological stimuli in comparison with pretreatment values.

It has been suggested from regression analysis of the relation between insulin and glucose levels (Seltzer et al., 1967) that a basic defect in diabetes is a diminished insulin secretion in response to a given rise in glucose: chlorpropamide therapy appears to make no difference to this impaired response, but to lower the level of hyperglycaemia at which it occurs (Chu et al., 1968 ), suggesting that this drug enhances the sensitivity but not the response of the $\beta$-cell. When the level of blood insulin obtained two hours after breakfast is related to the rise in blood glucose a comparison may be obtained with the figures of Seltzer et al. (who used a 100-g. glucose load after an overnight fast). The normal subjects give an index of 2.6 at two hours, which is less than that estimated from the data of Selter et al. (4.5) but consistent with a lesser glucose load. The " response" of the obese subjects who had no breakfast must be considered to show the variation of the method. The diabetic patients on diet alone show a lower index than the controls; those on sulphonylureas are also low, in keeping with the suggestion of Chu et al. (1968). The apparently " normal" index in the patients taking metformin can be interpreted as being due to a lesser rise in blood glucose from enhanced peripheral utilization affording less requirement for insulin secretion. The figures derived from the after-lunch and after-tea values are less comparable owing to the shorter period of fasting. In general, the index obtained is lower than that after breakfast. The present study was not designed to examine the individual patterns of insulin secretion after specific glucose loads, and these derived figures are presented only for purposes of comparison.

Weight reduction by dieting in obese diabetic patients produces a reduction in a previously excessive insulin response (Karam et al., 1965), and this variable affects all such "before and after" studies. We have not studied our patients before the initiation of treatment. If it is assumed that the groups are comparable the results available do suggest that there is no useful difference in the long-term control achieved by diet alone or by diet with either of the commonly used sulphonylureas. The mean preprandial level of insulin in the more obese metformin-treated group is significantly lower than in the diabetics on diet alone, suggesting that the diguanide drugs may be preferable if long-term complications are shown to be related to circulating insulin concentration. Similar results have been reported in preliminary form for patients treated with phenformin (cited by Danowski, 1967).

The greatest insulin response after the first of three equal meals during the day was consistently observed in all groups. This suggests that insulin synthesis and storage may proceed to a greater extent through the night than is possible in the short period between meals, and that the amount of insulin released may be determined not only by the carbohydrate load absorbed (Chu et al., 1968) but also by the amount of insulin which is available. 
In the obese patients on total starvation, free fatty acids were considerably raised without any variation throughout the day. Increase of free fatty acids during fasting in both obese and lean patients has been reported by Bloom et al. (1966). A fall in plasma insulin to a mean of $8.3 \mu \mathrm{u} . / \mathrm{ml}$. during eight days' fasting in normal non-obese subjects was recorded by Cahill et al. (1966). The raised levels still present in our own obese patients suggest that the response to starvation may be different between lean and obese subjects.

Treatment with diguanide drugs is known to result in a reduction in body weight of obese diabetic patients (Patel and Stowers, 1964 ; Schwartz et al., 1966). Clarke and Duncan (1968), in a carefully controlled long-term prospective study, found that most diabetic patients gained weight when taking chlorpropamide and tended to lose weight on metformin therapy. This is in keeping with our findings (Hadden et al., 1962), where the mean change in weight in 150 patients treated for nine months or more with chlorpropamide was $+5.8 \mathrm{lb}$. $(+2.6 \mathrm{~kg}$.). Nevertheless, there is no doubt that careful attention to diet will enable a satisfactory weight to be maintained regardless of additional sulphonylurea therapy, as shown by the satisfactory weight reduction of the patients in the present series who were taking the sulphonylurea drugs.

We are grateful to our colleague Dr. J. A. Weaver for his permission to study some of these patients; to Mr. D. W. Neill, clinical biochemist, Royal Victoria Hospital, for laboratory facilities; and to Dr. B. D. M. Grassick, Hoechst Pharmaceuticals Ltd., and Dr. C. Boroda, Rona Laboratories, for advice and financial assistance. One of us (A. N. R.) was in receipt of a postgraduate scholarship from the Northern Ireland Hospitals Authority, which was later extended into a Royal Victoria Hospital Fellowship.

\section{REFERENCES}

Abramson, E.; and Arky, R. A. (1967). Metabolism, 16, 204

Bloom, W. L., Azar. G. and Clark, J. E. (1966). Metabolism, 15, 401. Cahill, G. F. et al. (1966). \%. clin. Invest., 45, 1751.

Chu, Ping-Chi, Conway, M. J., Krouse, H. A., and Goodner, C. J. (1968). Ann. intern. Med., 68, 757.

Clarke, B. F., and Duncan, L. I. P (1968). Lancet, 1, 123.

Danowski, T. S. (1967). Metabolism, 16, 865 .

Danowski, T. S. (1967). Metabolism, 16, 865. 9, 122

Duncombe, W. G. (1964). Clin. chim. Acta, 9, 122. Diabetes, 11,91 .

Hales, C. N., and Randle, P. J. (1963). Biochem. f., 88, 137.

Hoffman, W. S. (1937). \%. brol. Chem., 120, S1.

Karam, J. H., Grodsky, G. M., Pavlatos, F. C., and Forsham, P. H. (1965) Lancet, 1, 286.

Marble, A. (1965). Med. clin. N. Amer., 49, 1137.

Patel, D. P., and Stowers, J. M. (1964). Lancet, 2, 282.

Reaven, G., and Dray, J. (1967). Diabetes, 16, 487.

Schwartz, M. J., Mirsky, S., and Shaefer, L. E. (1966). Metabolism, 15, 808 .

Seltzer, H. S., Allen, E. W., Herron, A. L., jun., and Brennan, M. T. (1967). 9. clin. Invesi., 46, 323.

Sheldon, J., Taylor, K. W., and Anderson, J. (1966). Metabolism, 15, 874.

\title{
Measles Vaccination with Reduced Dosage
}

\author{
R. G. HENDRICKSE,* M.D., F.R.C.P.ED., M.R.C.P. ; D. MONTEFIORE,* M.D., M.C.PATH., DIP.BACT.
}

Brit. med. F., 1968, 4, 28-30

\begin{abstract}
Cummary : A field trial is reported in which good sero$\checkmark$ conversion rates were obtained when a dose of 200 TCID $_{50}$ Beckenham 31 strain (Wellcovax) measles vaccine was administered by Ped-O-Jet subcutaneously in a volume of $0.5 \mathrm{ml}$. per dose. It is suggested that use of this reduced dosage would lead to a significant reduction in the cost per dose of the vaccine, especially when administered on a scale large enough to justify the use of multidose containers.
\end{abstract}

\section{Introduction}

Widespread immunization against measles is currently being undertaken in several developing countries with outside financial assistance. The health authorities in these countries will eventually be faced with the problem of maintaining the immunity status of their child populations once the assisted schemes come to an end.

Measles vaccine is expensive even when administered to relatively large groups of children and multidose containers are used. Containers for single or small numbers of doses are relatively more expensive, since a fairly large proportion of the total cost is absorbed in ampouling. This high cost of measles vaccine is likely to present serious problems in many areas and may deter authorities from using the vaccine (Cooper et al., 1966). If adequate immunization was achieved with a lower dose of vaccine than is currently being used, there could be a significant reduction in the cost. It seemed worth while,

\footnotetext{
- Departments of Paediatrics and Medical Microbiology, University of Ibadan, Nigeria.
}

therefore, to investigate the immunizing potential of reduced doses of measles vaccine administered by the same technique and under similar field conditions to those obtaining in most countries where mass vaccination campaigns are currently in progress.

We report here the results of such a trial, which was undertaken in a rural area of Kwara State, Nigeria.

\section{Methods and Materials}

Vaccination was offered for children aged 6 months to 3 years ; in the event, a small number who were younger than these also attended, and there were also a few who were up to 4 years old.

Each child was registered, and a numbered card was completed giving its name, age, and sex; a duplicate numbered card was given to the parent bringing the child.

After registration the first 191 children had pre-vaccination blood samples taken: these were obtained by finger-prick, and the sample was absorbed on to numbered filter-paper discs which contained $0.2 \mathrm{ml}$. of blood when fully saturated. The rest of the children attending were vaccinated (see below) but no pre-vaccination blood samples were taken.

After vaccination each child was given a suitable dose of pyrimethamine to prevent any attack of malaria during the period when vaccination reactions might be expected, and was told to return to the clinic in four weeks' time, bringing the duplicate registration card. Post-vaccination finger-prick blood samples were taken from all children who had been bled initially 